\title{
Relevance of Social Responsibility in the Pandemic Era - An Indian Perspective
}

http://doi.org/10.21272/bel.5(3).79-86.2021

George Abraham Kurian, ORCID: https://orcid.org/0000-0002-4511-3856

Practicing Chartered Accountant, Director, VitalSource Knowledge Associates P.Ltd., Edtech Project Consultant - Virtuedge Management Services P.Ltd, India

\begin{abstract}
As the world's largest democracy and the second most populated country globally, India has had a relatively severe adverse impact of the pandemic than most other countries. This research paper highlights key pandemic implications on India's socially responsible initiatives and how these affect citizens. This once-in-a-century global health disaster turned out to be a sustainable development crisis for most nations. Due to pandemic ramifications, the worldwide progress on Sustainable Development Goals (SDGs) adopted in 2015 in its current form, has recorded reversal in several critical indices, despite the limitations of underestimating due to lack of latest or reliable data. While the pandemic has posed serious challenges to attaining country-specific SDGs, it also provided opportunities to demonstrate socially responsible behavior amidst the crisis. This paper deliberates on the individual roles and the interplay between four pillars of socially responsible behavior, meaning the government, corporate sector, social sector, and the civil society at large comprising of individuals, groups, and communities operating outside of the government and for-profit and NGO entities. The study delves in depth into key SDGs that suffered setbacks due to disruptions and health emergencies that assumed higher priority. The authorities were compelled to change course from plans. The priorities planned through Government policies had to be modified on an urgent basis, as government was also taken unawares and had to safeguard the lives and livelihood of the population. Benchmarking of SDGs was done at a country and state level. It reflects the gaps in what was attained at the highest and lowest level by various states and union territories and likely areas of improvement.
\end{abstract}

Keywords: Social Responsibility, Sustainable Development Goals, No Poverty, Zero Hunger, Quality Education, Gender Equality, Reduced Inequality, Clean Air and Sanitation, Healthcare, Corporate Social Responsibility.

JEL Classification: M14, Q01, Q53, I3, I0, I14.

Cite as: Kurian, G.A. (2021). Relevance of Social Responsibility in the Pandemic Era - An Indian Perspective. Business Ethics and Leadership, 5(3), 79-86. http://doi.org/10.21272/bel.5(3).79-86.2021.

Received: 15 July $2021 \quad$ Accepted: 28 August $2021 \quad$ Published: 13 September 2021

Copyright: (C) 2021 by the author. Licensee Sumy State University, Ukraine. This article is an open access article distributed under the terms and conditions of the Creative Commons Attribution (CC BY) license (https://creativecommons.org/licenses/by/4.0/).

\section{Introduction}

India has been pursuing its UN-backed SDGs and measuring progress at country and state-specific levels as a member of a forum of 193 countries. Despite commendable advances made in several development SDGs over past years, budgetary allocations made over the past few decades in poverty eradication, healthcare, and education, as expressed in GDP terms, do not appear commensurate with the size and growth of its population, and as compared to peer countries. These reflect quite low scores in some key SDG indices. According to the Sustainable Development Report [SDR] 2021, authored by Prof Jeffrey Sachs and colleagues at the Sustainable Development Solutions Network (SDSN), a UN project quotes that India's worldwide ranking in SDGs fell from 115 in 2019 to 117 in 2020, and to 120 in 2021. The SDR 2021 specifically noted India's declining trends in Quality Education (SDG 4) and Life on Land (SDG 15), while there was no significant progress recorded in some SDGs that included Zero Hunger (SDG 2), Gender Equality (SDG 5), Sustainable Cities and Communities (SDG 11), Peace, Justice Strong Institutions (SDG 16) and Partnerships for Goals (SDG 17).

The study "State of Working India 2021 - One Year of Covid-19" has touched upon several aspects of the state of the Indian economy. Global Multidimensional Poverty Index 2020 Report places India at 62nd rank among 107 countries with an MPI score of 0.123 and identified $27.9 \%$ population as multi-dimensionally poor, [of which $36.8 \%$ was rural and 9.2\% urban]. While the period 2005-2016 witnessed the fastest reduction 
in poverty in terms of Below Poverty Line [BPL] by UN standards of US\$ 1.90 per day, the progress thereafter has not been on similar lines and is now aggravated by the pandemic.

This study has touched upon several aspects of the state of the Indian economy. It states that 23 million Indians are back into poverty and gaining back lost ground, is expected to take long. Achieving the poverty eradiation goal set of below $6 \%$ by 2030 looks over-optimistic. This report highlights the following:

$>$ The economic damage caused by the Covid-19 pandemic was immense. With no social protection available through employment for many and with a safety net mostly based on domicile, the poorest households suffered the worst, mainly income losses. These included self-employed and casual workers, who account for 45 percent of total urban employment.

$>$ A severe supply and demand shock caused by the economic downturn before the pandemic resulted in job and earnings losses. As a result, informality and food insecurity aggravated, and so did poverty and inequality.

$>$ Due to pandemic effects, salaried permanent jobs were retained only by $47.6 \%$ in that category. Of the remaining $9.8 \%$ joined the ranks of daily wage or casual labor force, $8.5 \%$ were temporarily salaried, while $34.1 \%$ became self-employed.

The prevailing situation compelled the poorest households to avail loans commensurate to their earnings. Since many of these loans were obtained from private lenders at exorbitant interest rates, the financial standing of borrowers might be in jeopardy.

230 million more people slipped below the national minimum wage poverty threshold.

$>7 \%$ of men and $46.6 \%$ of women lost their jobs during a pandemic. The study pointed out that while men were more likely to shift to the informal sector due to their greater flexibility, women were more likely to leave the labour market in such circumstances.

$>$ Increase in crime rate, domestic violence and crime against women and children were noted during Covid-19.

$>$ Orphaned children were being exploited during Covid-19.

\section{SDG-1-No-Poverty}

The number of poor in India increased by 75 million due to Covid 19, accounting for nearly $60 \%$ of global poverty. According to Forbes, the number of billionaires in India rose from 102 to 140 in the last year. Inequitable distribution of the proceeds of growth thus poses a significant challenge for India. India, home to the largest number of poor by international standards, faced disastrous consequences in the initial phases due to extended lockdowns and mass exodus of migrant labor. During the pandemic, the poor suffered more by losing jobs, income and consequent inability to meet necessities and healthcare needs. The government has launched multiple schemes to reduce poverty but with limited impact in recent years due to the magnitude and nature of the problem.

\section{SDG 2 - Zero Hunger}

United Nations states that the aim of SDG 2 is to end hunger and all forms of malnutrition by 2030. The vision is to end hunger, malnutrition, achieve food security, eliminate loss or waste of food and promote agriculture. Most of the people suffering from hunger belong to developing countries in South Asia and Sub-Saharan Africa. It was estimated that between 720-811 million people in the world will face hunger in 2020. In 2020, India ranked $94^{\text {th }}(27.2$ score $)$ out of 107 countries in Global Hunger Index. This score indicates that India is facing serious hunger issues. National Food Security Mission is a centrally sponsored scheme to increase production through area expansion and productivity; create employment opportunities and enhance the farm profits to restore the confidence of farmers.

Mid-Day Meal Scheme - This provides a continuous measure of food security to millions of school-going children across India. This scheme directly impacts the goal of Zero Hunger. The Food Security Act (2013) also known as the 'Right to Food Act' is an Indian Act of Parliament that aims to provide subsidized food grain to cover up to $75 \%$ for rural population and $50 \%$ for the urban population. These are some missions adopted by India Government to achieve the Zero Hunger objective. The Indian government provided extra rations through a targeted public distribution system and free distribution of food grains and pulses per month during the pandemic. Private sector-provided food kits were distributed to many school students deprived of mid-day meals. Youth group coordinated with local authorities and NGOs to distribute food packets, vegetable kits and 
daily essentials to those infected and isolated in their communities. While improving, the public distribution system still faces wastage and losses through pilferage, inefficient storage and distribution, poor quality, fake ration cards, black marketing, adulteration, etc. Automation of ration cards has reduced these issues significantly in recent years. However, the lack of central-state government coordination in pandemic times affected the offtake. The disparity between urban-rural, rich-poor, gender inequalities leading to food insecurity was a recent challenge. Achieving Zero Hunger is difficult, especially due to Covid-19 but not impossible.

\section{SDG 3 - Good Health and Wellbeing}

As per the 2020 Agenda for Sustainable Development, the motto was to ensure healthy lives and promote wellbeing for everyone irrespective of age. SDG Index score for goal 3 in 2018 was 52, which rose to 61 in 2019 and continued its progress in 2020 with 74 in the pandemic era. In state-wise SDG Index scores, Gujarat and Delhi are the top performers among the States and the UTs, respectively, while the least performer was Assam (NITI Aayog, 2021). According to a Sunday Guardian report, India has among the lowest public healthcare budget in the world, of just $1.26 \%$ of the total GDP currently (2020-2021). In stark contrast, the U.S. spent nearly $16 \%$ of its GDP on public health care, while France and Germany spent over 10\% of GDP, according to data from the World Bank. Neighboring countries Bangladesh and Pakistan also spent over 3\% of their GDP on public healthcare.

\section{n Hospital Beds (per 10,000 People) \\ Physicians (per 10,000 People)}

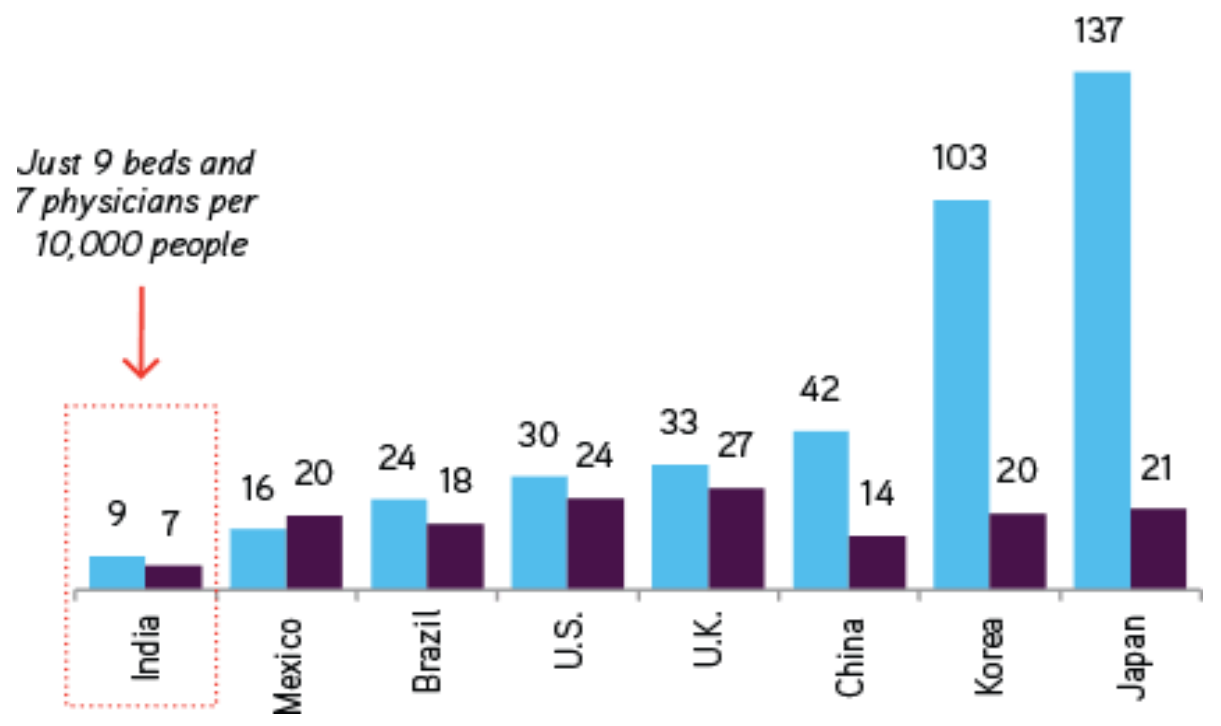

Figure 1. Doctor to Population Ratio

Source: Pristyn Care - Health Care Industry -30 years of struggle in India

According to the Finance Commission report on February 2021, every allopathic doctor in India caters to at least 1,511 people, much higher than the World Health Organization's norm of one doctor for every 1,000 people. State-wise, this ratio varies widely, ranging from 380 in Goa to 17,060 in Nagaland. The shortage of trained nurses is even more dire, with a nurse-to-population ratio of 1:670 against the WHO norm of 1:300. Kerala has the best numbers, with 111 people per trained nurse, while Jharkhand is last with 4,019. Brazil accounts for doctor to 1000 population ratio of 2.320, while Canada at 2.8 and China at 2.24 while Sri Lanka has 1.0 doctor to 1000 people (according to Global Family Medicine - Srilanka 2019).

\section{Beds to Population Ratio}

India is estimated to have $18,99,228$ hospital beds (over 60 percent of which are in the private sector), roughly 1.4 beds per 1,000 population. It is lower than in many comparable countries: in comparison China's four beds per 1,000. Sri Lanka, the United Kingdom, and the United States have three beds per 1,000; Thailand and Brazil exceed two beds per 1,000 persons. Even adjoining Bangladesh is marginally better as it has eight beds per 1000 according to December 2020 news in Times of India newspaper. 


\section{SDG 4 - Quality Education}

The pandemic had a disastrous impact on the education system in India, with most students unable to attend or pursue schools and college education uninterrupted, during 20-21 due to series of lockdowns and risks of infection spread. An additional 101 million children (approximately $9 \%$ of primary and lower secondary school children) fell below the minimal reading competency criterion due to the pandemic, bringing the total number of kids falling behind to 584 million until 2020. It negates the advances made in education over the last 20 years. Almost two-thirds of the youngsters so lagging in education are from Central and Southern Asia, as well as Eastern and South-Eastern Asia (according to UN SDG Report 2021).

The SDG Index Score on Goal 4 for India stands at 58. Among the States, Kerala is the top performer, and Chandigarh, among the UTs. The positive side was that rapid advances were made through IT penetration to fill this gap, with online education and E-learning modes using online platforms but mainly benefited the middle and upper class and mainly in the urban areas. The process of reaching technology to schools and colleges, home computers and mobile handsets with affordable internet connectivity, especially to the economically weaker sections, is being accorded high priority given its ramifications on employment and skill development. It is being addressed through various government schemes with active assistance from the IT private sector.

\section{SDG 5 - Gender Equality}

The goal aims to achieve a discrimination-free society. The countries must develop legal policies on women's health, sexual exploitation and end harmful practices like early or child marriage, child trafficking, and female genital mutilation. The overall score of India in the SDG India 2021 - NITI Aayog report for SDG 5 is 48. The Best states are Chhattisgarh (64) and Kerala (63). The worst states are Arunachal Pradesh 37) and Assam (25). The best UTs are Andaman and Nicobar Islands (68) and Puducherry (66). The worst UTs are Ladakh (46) and Delhi (33) (NITI Aayog - SDG India Index, 2021).

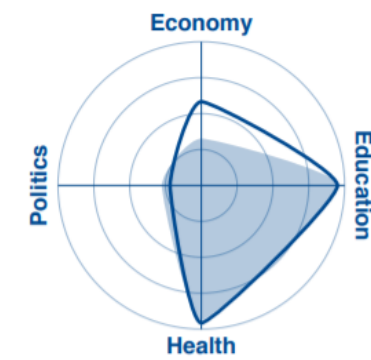

Global Gender Gap Index Economic participation and opportunity Educational attainment Health and survival Political empowerment

\begin{tabular}{rrrr}
\multicolumn{2}{c}{2006 score } & \multicolumn{2}{r}{2021 score } \\
98 & 0.601 & 140 & 0.625 \\
110 & 0.397 & 151 & 0.326 \\
102 & 0.819 & 114 & 0.962 \\
103 & 0.962 & 155 & 0.937 \\
20 & 0.227 & 51 & 0.276
\end{tabular}

0.276

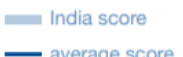

Figure 2. The Gender Gap Index of 2021 Ranked India 140 out of 156 Countries

Source: Global Gender Gap Report, 2021

In India, the sex ratio at birth is 899 girls for every 1000 boys. (Sample Registration System (SRS) Statistical Report 2018). Chhattisgarh and Kerala are the highest at 958 and 957 respectively. Haryana and Uttarakhand are the lowest at 843 and 840 respectively. (National Family Health Survey, 2019-2020). Political representation as of 2021, the Lok Sabha has 14\%, the Rajya Sabha has $11.6 \%$ and the State Legislative Assemblies had $8.46 \%$ of women leaders. (Lok Sabha \& Rajya Sabha, 2021). The World Bank data shows India's Female Labor Force Participation Rate (FLFPR) has reduced to $20.79 \%$ in 2019 as compared to $31.79 \%$ in 2005 (World Bank- India FLFPR, 2021).

In India, the pandemic has exacerbated existing discrimination, violence, and crimes against women. Of every 100,000 women, 20 have experienced physical violence by their husbands or relatives. Assam has the highest number of victims in states at 71, and the lowest is in Nagaland at 4 for domestic violence. UT Delhi stands the highest at 41 and the lowest in Puducherry at 12 (NITI Aayog-SDG India Index, 2021). The government has declared women's violence prevention and survivor support as "Essential Service" (The Times of India, March 2021). Due to financial crisis, children belonging to economically weaker sections of the society are exploited, married off, forced to labor, and victims of child trafficking. According to UNICEF, up to ten million girls will be in danger of underage marriage in 2021-2030 (UNICEF, 2021). According to data gathered by Bachpan Bachao Andolan (BBA), 9,000 children were rescued while being kidnapped for labor between April 2020 
and June 2021 (BBA, 2021). The Supreme court has requested PM CARES fund to take up the maintenance of children orphaned by Covid-19 till they reach age 18 (The Hindu, August 2021).

The Prime Minister's Beti Bacha Beti Padhao program seeks to provide equal opportunity and education for girls in India. The Sukanya Samridhi Yojana scheme facilitates proper education and carefree marriage expense for the girl child. The Janani Suraksha Yojana is a safe motherhood intervention for poor pregnant women. Ujjawala is a Comprehensive Scheme to prevent women and children from commercial sexual exploitation. Swadhar Greh targets women victims of difficult circumstances who need institutional support for rehabilitation (MWCD, 2021).

\section{Need for a Socially Responsible Outlook}

The principles of Social Responsibility include ethical actions, legal aspects, economic interests and philanthropic responsibilities. Being socially responsible requires an altruistic mindset with empathy towards others who are lesser privileged. If we were to consider the constituents of a social responsibility framework in a pandemic scenario as four quadrants, it can be classified as:

$>$ Public sector and authorities representing Government [Quadrant 1].

$>$ Private sector representing companies mandated to do CSR [Quadrant 2].

$>$ Social sector including NPOs and NGOs [Quadrant 3].

$>$ Civil society including individuals, firms, societies and smaller businesses [Quadrant 4].

Quadrant 1 - Governmental Role and Responsibilities. In the Indian democratic setup, elected governments, whether at the Centre, State or Union Territory level, have the primary legislative role for their citizens' social well-being and are expected to carry out their responsibilities in line with public expectations. Good governance must complement an impartial judiciary and a proactive civil, administrative machinery that efficiently implements the policies and statutes as intended and on time. Accountability, transparency and level of responsiveness to address genuine concerns of various sections of the population, balancing conflicting interests, is also the hallmark of good leadership.

Indian governance at Centre and State level faced a natural disaster of unprecedented proportions, and with respect, they carried out the role of pandemic control to the best of their abilities. Several challenges and decisions were taken from a political and economic perspective which seemed deficient in specific instances. One crucial area was the need for better coordination and cooperation between the Centre and state governments in enforcing public policies and restrictions that would have led to better outcomes and needs improvement going forward. Retail pricing of petroleum products is an area where the Government must take decisions discretely balancing conflicting interests but was harsh in reducing the purchasing power of the poor due to its cascading effect on prices of other goods.

Quadrant 2 - Corporate Sector CSR. The rationale behind CSR is for corporate sector to pursue social and environmental objectives, in addition to their primary objective of maximizing profits. Under the Companies Act 2013, certain classes of profitable and large companies are required to spend at least $2 \%$ of their 3-year average net profit towards CSR activities in a particular financial year for supporting causes listed in Schedule VII of the Act. CSR has a pivotal role during the pandemic and rose to its expected potential during the crisis. India's CSR spend by companies obliged to do so, increased over the years since 2013-14 when it was first legal mandated. From an average of below Rs.10,000 crores per annum, it shot up to a record Rs.21,270 crores in the pandemic period of FY 2020 and aggregate CSR spend till date crossed the historical milestone of Rs. 100,000 crores since inception in 2013. In the FY 2021, though the figures are not finalized, it is likely that the minimum mandated spend of 2\%, will be around Rs. 22,000 crores (Indian Institute of Corporate Affairs - IICA, Delhi, 2021).

This spurt in CSR spending was also attributable to tightening of the mandatory spending clauses of Section 135 of the Companies Act 2013, making it compulsory for the obligated companies to park the unspent amount of CSR projects in progress at the end of the year, to a designated bank account within 30 days of the financial year-end and spend it within three years or transfer unspent amounts to the specified government accounts. Any other amount out of the mandated $2 \%$ spend, not allocated for specific CSR projects at the year-end, will have to be similarly transferred to the specified Government National Relief Funds within six months. Earlier, the companies had to merely provide a reason for not spending in the Board of Directors report for not spending CSR mandated amounts. Earlier, the companies had to merely provide a reason for not spending CSR mandated amounts in the Board of Directors report. 
Quadrant 3: Role of NGOs and NPOs. The role of the social sector comprising NGOs and NPOs, is crucial to a country like India. The aid received from domestic and overseas finds its ways into areas and segments where government, public and private [CSR mandated] sector, cannot or will not reach. This mainly represents the marginalized and backward sections and the vast rural areas comprising over 650,000 villages that suffer without basic infrastructure due to the pandemic. With the declared interest of national security, the Union Government, preventing terrorist acts and anti-conversion objects, tightened the Foreign Contributions Regulations Act [FCRA] before the onset of Covid, making it far more stringent for accepting foreign contributions NGOs in India. Such remittances can now be received only by a FCRA registered Trust or with prior permission from the Union Ministry of Home Affairs.

Restrictions imposed include denying permissions to FCRA Trusts to route the charitable contributions through other trusts or any person, other than the intended beneficiaries; capping of $20 \%$ on administrative expenses, including research and managerial staff salaries; routing of all funds through a specified branch of State Bank of India, Delhi; maintaining separate accounts of foreign funds and giving power for quarterly inspection, etc. While justifiable to an extent, these government policies and restrictions were imposed in pandemic times have adversely impacted the ability of several FCRA NGOs, particularly those that are India offices of internationally affiliated social, religious and charitable organizations.

The apex NGOs carry out their charitable objectives by transferring funds to other grassroot level NGOs operating in rural India. These grassroot NGO personnel directly interact with target beneficiaries and funds are used to provide aid and implement projects and initiatives mainly in poverty alleviation, healthcare, education, livelihood, etc. There are only around 22,000 FCRA registered NGOs in India, out of the 3,000,000 plus registered NGOs in India. The numbers will dwindle further as there are periodical renewals and many such NGOs may find the restrictions onerous and impracticable. These NGOs have also been provided the option under the Act to surrender their FCRA licenses.

Since a substantial number of the domestic NGOs were established for dubious causes, not complying with applicable regulations, and involved in tax evasion and other illegal or fraudulent activities, the Government has made a recent change making it mandatory for all trusts to re-register under the Income Tax Act to retain their income tax exemption and also to closely monitor their activities harnessing technology, going forward. Though restrictive and stringently implemented when India is struggling with the aftershocks of the pandemic onslaught, the above regulations serve as a wake-up call for NGOs to be socially responsible and carry out their charitable objectives with genuinely altruistic intents and function in an accountable and transparent manner. It is now imperative that trustees act within the framework of law and do justice to their fiduciary roles.

Quadrant 4: Individuals, Firms, Societies and Non-CSR Mandated Businesses. Individual Social Responsibility is quite pervasive and transcends all the other quadrants of responsibility as it is human beings who comprise the public and private sector entities in other quadrants. This Quadrant 4, comprising wellmeaning individuals or groups, played a pivotal role in supporting government, social and environmental initiatives, especially during difficult pandemic times that witnessed the lesser privileged and vulnerable classes suffering in various ways.

Medical Fraternity and Other Service Personnel. Doctors, nurses and other healthcare-related including personnel, policemen, sanitation staff, faced difficult times and work when hospitals find it hard to cope with the patients who could not be easily attended to, due to lack of adequate infrastructure in several states during the first and second pandemic wave. These were several instances of individual socially responsible behavior as many risked or lost their lives for the cause of caregiving for the suffering and the deceased patients. Similarly, many individuals and groups went out of their way to provide food, water, and clothing, to migrant labor who were walking in large groups in panic for days to reach their home villages. The migrant labor who was walking barefoot in large groups in panic for days to reach their home villages. Many factories, manufacturing, and service units, worked multiple shifts to supply vaccines, medicines, PPE kits and other medical disposables or were temporarily converted to undertake or increase production of healthcare and other essentials demonstrated acceptable socially responsible behavior.

Pricing of Healthcare and Essential Products. Overpricing of products by businesses, particularly for healthcare and essential goods with disproportionate profit margins to take advantage of shortages during the pandemic, was rampant, particularly in some parts of India. During the pandemic lockdown, many drugs, pharmaceuticals, medical equipment and consumable suppliers witnessed unprecedented demand for their products and so did hospitals and diagnostic labs for their services. As the pandemic worsened, specific drugs, 
testing kits, PPE kits, surgical masks, oxygenators, oxygen cylinders/refills, vaccines and hospital services witnessed shortages since there was frantic rush and panic buying at exorbitant prices. Even ambulances started charging several times the usual fare, to transport patients to hospitals or corpses to cremation or burial grounds. Health authorities were finding it challenging to meet the unprecedented demand. Major suppliers from China had jacked up prices manifold for basic drug formulations and oxygenators to capitalize on global demand and supply shortage, due to pandemic. Numerous instances of profiteering and hoarding of these essential and life-saving goods and services were reported leading to suffering and loss of lives. Many individuals resort to panic buying to the detriment of others. Glaring instances were reported, where public and local authorities were unable to control or, worse still, endorsed these unethical practices in essentials and healthcare supplies during the crisis.

WFH and Online Learning. Automation got a significant boost due to pandemic and many businesses using IT and ITES were lesser affected due to the option to allow people to work from home (WFH) or learn online, except in cases where staff had to attend physically. It is an instance of socially responsible behavior and adherence to social distancing norms.

\section{Conclusion}

Since the mortality rate soared across the country, tens of thousands of people from all walks of life died due to lack of medicines, difficulty in procuring hospital beds, and lack of medical treatment. For the multitude, there were affordability issues too, and many had no health insurance covers. When government, judiciary, and public authorities were grappling with pandemic emergencies in trying to equitably distribute scarce resources, socially and ethically irresponsible behavior was also rampant in the ensuing confusion, including corruption, dishonesty, and capitalizing on the misfortunate of fellow beings. Those indulging in such acts would do well to introspect whether their actions were socially responsible or humanitarian amidst a raging pandemic. Notwithstanding these aberrations, a large section of Indians from all walks of life worked tirelessly and, in many instances, went far beyond the call of duty to alleviate the sufferings of fellow citizens in their local community through providing healthcare and other vital assistance to support governmental initiatives in reaching essential goods and services where it was needed most.

Funding. There is no funding for this research.

\section{References}

1. Bachpan Bachao Andolan (BBA) (2021). Over 9000 trafficked kids rescued by law enforcement agencies and BBA since beginning of covid. Available at: [Link]

2. Finance commission report (2021). Available at: [Link]

3. Fitch Solutions (2021). Resurgence of Covid-19 Infections Will Take a Toll on Indian Healthcare System. Fitch report by Pharma \& Healthcare India. Available at: [Link]

4. Ghosh, A. (2021). 1 doctor for 1,511 people, 1 nurse for 670 - Covid exposes India's healthcare 'fault lines'. The Print. Available at: [Link]

5. Karmali, N. (2020). India's 100 Richest 2020: Collective Net Worth of Country's Richest Rose 14\% Despite Pandemic. Forbes. Available at: [Link]

6. Kochhar, R. (2021). In the pandemic, India's middle class shrinks and poverty spreads while China sees smaller changes. Pew Research Center 2021. Available at: [Link]

7. List of NGOs providing relief during Covid-19 (2021). Available at: [Link]

8. List of United Nation Member Countries with joining date (2012). Available at: [Link]

9. Lokur, M.B., Narayan, S. (2021). The long road to winning the battle against trafficking. The Hindu. Available at: [Link]

10.Mid-day meal scheme. Ministry of Education Government of India (2019). Available at: [Link]

11.Ministry of Health and Family Welfare (2020-2021). The annual report of the ministry of health and family welfare. Available at: [Link]

12.Misra, S.S., Patel, T. (2021). The Inequality Virus - India Supplement 2021. Oxfam India. Available at: [Link]

13.Mondal, D. (2021). India spends just $1.26 \%$ of GDP on public healthcare. Sunday guardian report. Available at: [Link]

14.NITI Aayog SDG India Index (2021). Available at: [Link]

15.Oxfam India (2021). Inequality Report 2021: India's Unequal Healthcare Story. Available at: [Link]

16.Pristincare (2021). Healthcare Industry: 30 Years of Struggle in India. Available at: [Link] 
17.Rajagopal, K. (2021). Can PM-CARES Fund help children orphaned by COVID-19, asks Supreme Court The Hindu. Available at: [Link]

18.Sabha, L. (2021). Women Representation. Available at: [Link]

19.Sabha, R. (2021). Women Representation. Available at: [Link]

20.Sachin, P.M. (2021). India's spending on CSR. Available at: [Link]

21.SDGs Report 2021 - [Quality Education] United Nations Statistics Division 2021 report. Available at: [Link] 22.SRS-Statistical Report (2018). Available at: [Link]

23.The state of food security and nutrition in the world (2021). Available at: [Link]

24.Times of India (2021). Complaints of domestic violence against women spiked in year of lockdown: NCW Data. Available at: [Link]

25.Times of India (2020). The role of NGOs - Ensuring commitment to social responsibility amidst the Covid19 pandemic. Available at: [Link]

26.Unicef (2021). 10 million additional girls at risk of child marriage due to COVID-19. Available at: [Link] 27.World Bank - India Female Labour Force Participation Rate (2019). Available at: [Link]

28.World Economic Forum (2021). Global Gender Gap Report. Available at: [Link] 